\title{
The Research of the Relationship between Low Carbon-Based Marketing Innovation and Organizational Performance
}

\author{
Baoqian Wang, Xianyan Zheng \\ Business School, Hohai University, Nanjing, China \\ Email: bq64@163.com, zxy870329@163.com
}

Received April 15, 2013; revised May 15, 2013; accepted May 26, 2013

Copyright (C) 2013 Baoqian Wang, Xianyan Zheng. This is an open access article distributed under the Creative Commons Attribution License, which permits unrestricted use, distribution, and reproduction in any medium, provided the original work is properly cited.

\begin{abstract}
Based on relevant literature, this study attempts to provide a conceptual model for how green complex orientation influences organizational performance by using low carbon-based incremental marketing innovation and low carbonbased radical marketing innovation as mediator, 213 firms from Jiangsu province were investigated as empirical samples. The results show that low carbon-based marketing innovation plays a complete role in mediating the relationship between green complex orientation and organizational performance, low carbon-based incremental marketing innovation plays a complete role in mediating the relationship between green market orientation and organizational performance, and low carbon-based radical marketing innovation plays a complete role in mediating the relationship between green innovation orientation and organizational performance.
\end{abstract}

Keywords: Low Carbon; Marketing Innovation; Organizational Performance

\section{Introduction}

Many scholars believe that the market orientation can promote companies' innovation ability, accelerate the speed of developing new products, raise the customer satisfaction, and hence it influences the performance. Only do the enterprises implement marketing orientation seriously they can listen carefully to the voice of customers, integrate detailed market information into organizational learning and then they promote the incremental marketing innovation of the organization. Innovation orientation reflects two modes. One is "promotion driven by technology" and the other is "promotion driven by market". Innovation orientation represents the enterprise's attention to potential demand and future demand of customers. Radical marketing innovation makes "voice of future technology" and "voice of future market mode" the priority, which increasingly emphasizes the market prediction so as to create demand for the product or service.

Both market orientation and innovation orientation can create a successful enterprise, while the former pays attention to the practical needs of customers, the latter concerns the potential needs and future needs of customers. Scholars like Simpson; Siguaw and Enz [1] had proposed a synergistic effect combining market orientation and innovation orientation, namely complex orientation. Does green innovation orientation of green complex orientation have a positive impact on low carbon-based incremental marketing innovation? By using the low carbon marketing innovation as the mediator between green complex orientation and organizational performance, this article investigates the mediator effects that low carbon marketing innovation imposed on the complex orientation and organization performance.

Innovation orientation will promote radical marketing innovation based on technology and market. The effective combination of the two orientations will stimulate organization in meeting customer's present demand, even as well as the potentials. Simpson; Siguaw and Enz pointed out that should implement innovation orientation during the process of implementing market orientation, so as to make use of the advantages of both, hence better satisfy customer demand. Berthon et al. [2] constructed the $2 \times$ 2 matrix with market orientation and innovation orientation as two dimensions, and distinguishes four different kinds of enterprises. Enterprises which locate in the high position of both mentions have a higher degree of market orientation and innovation orientation. Green complex orientation can insight subtle changes of market, search 
customer's potential and future green demand which will be included in the content of organization study and then promote the organization's low carbon marketing innovation. In order to simplify, this study integrates radical marketing innovation based on both technology and market as one variable, simply radical marketing innovation. From the above analysis, this study proposes the assumptions as follows:

H1: Green market orientation (GMO) has significantly positive effects on low carbon-based incremental marketing innovation (LIMI).

$\mathrm{H} 2$ : Green market orientation (GMO) has significantly positive effects on low carbon-based radical marketing innovation (LRMI).

H3: Green innovation orientation (GIO) has significantly positive effects on low carbon-based incremental marketing innovation (LIMI).

H4: Green innovation orientation (GIO) has significantly positive effects on low carbon-based radical marketing innovation(LRMI).

H5: Low carbon-based incremental marketing innovation (LIMI) has significantly positive effects on organizational performance $(\mathrm{OP})$.

H6: Low carbon-based radical marketing innovation (LRMI) has significantly positive effects on organizational performance (OP).

Based on the above analyses, this study introduces low carbon marketing innovation as mediator into study of the relationship of green complex orientation and organizational performance, and divides low carbon marketing innovation into low carbon-based radical marketing innovation and low carbon-based incremental marketing innovation, and constructs a theoretical linkage model of relation of green complex orientation-low carbon marketing innovation - organizational performance, thus gets causal relationship model of different research variables. Shown as Figure 1.

1) Green market orientation: it pays attention to the practical needs of customers; Green innovation orientation: it concerns the potential needs and future needs of customers.

2) Incremental marketing innovation: Based on the existing technology modes, we make incremental improvements on products so as to provide new function of it; Radical marketing innovation: Based on the new tech-

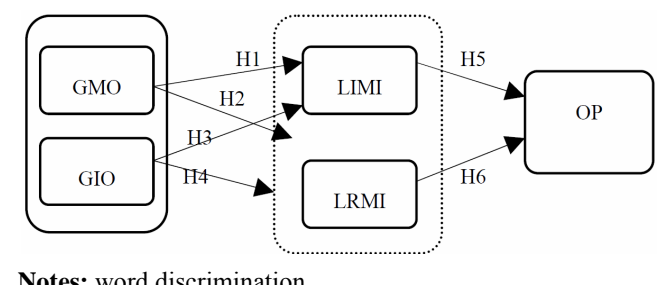

Figure 1. Assumption relation in the theoretical mode. nology modes, we create new demands that not identified by customers.

\section{Model Establishment and Empirical Analysis}

Research invited executives to fill in the questionnaire, distributed a total of 246 questionnaires, withdrew 232 questionnaires, of which the effective questionnaire was 213 , and the total effective recovery rate was $86.59 \%$. Shown as Table 1.

\subsection{Scale Design}

For the scale design of low carbon-based incremental marketing innovation and low carbon-based radical marketing innovation, the scales design mainly consult Caiming Da (Taiwan) [3]. The scale of product innovation, Lixian Jiang [4]. The scale of incremental and radical product innovation, Zhou et al. [5]. The scale of radical product innovation, Kumar [6]. The description of the value proposition of $3 \mathrm{~V}$ list in innovation dimensions of low carbon value proposition and add the concept of low carbon. They consult Caiming Da (Taiwan) [3]. The innovation scale of marketing program, Lixian Jiang [4]. The innovation scale of incremental and radical marketing program, Kumar [6]. The description of value net of $3 \mathrm{~V}$ list in innovation dimensions of value net and add the concept of low carbon. All scales use likert5 magnitude scale.

In the process of questionnaire survey, it easily emerges single source bias (CMV) for each questionnaire filled in by the same people. We test this study with Harman single factor test methods, all items of the questionnaire with factor analysis and find that the first principal component not rotated accounts for $18.319 \%$ of load capacity showing that this questionnaire has no obvious CMV.

\subsection{Factor Analysis}

This study is based on 213 samples of exploratory factor analysis (EFA), confirmatory factor analysis (CFA), correlation analysis, and Cronbach's $\alpha$ test.

Green market-oriented exploratory factor analysis: In this study, we extract three factors and 14 items with principal component analysis, factor loadings is greater than 0.7 , of which factor loading minimum is 0.721 . The KMO test value of 14 items is 0.793 , chi-square value of Bartlett sphericity test is 172.083 (df is $74, p$ is 0.000 ), indicating that it is more suitable for factor analysis. Each items of three factors significantly correlated at the 0.01 level. Three factors extracted with maximum orthogonal variance (Varimax) rotation explain $69.328 \%$ of the total variance and show that the green market-oriented scale's design and results have good consistency. 
Table 1. The basic characteristics of the sample.

\begin{tabular}{|c|c|c|c|c|c|}
\hline Characteristic & Category & Proportion & Characteristic & Category & Proportion \\
\hline \multirow{2}{*}{$\begin{array}{c}\text { Staff } \\
\text { Quantity/person }\end{array}$} & $<300$ & $44.7 \%$ & \multirow[b]{2}{*}{ Company's techno sphere } & Fast moving consumer goods & $29.2 \%$ \\
\hline & $300 \sim 2000$ & $39.8 \%$ & & Durable consumer goods & $21.6 \%$ \\
\hline \multirow{5}{*}{ Company age/year } & $<5$ & $18.2 \%$ & \multirow{5}{*}{ Enterprise asset scale/million } & $<50$ & $3.1 \%$ \\
\hline & $5 \sim 10$ & $30.9 \%$ & & $50 \sim 100$ & $14.2 \%$ \\
\hline & $11 \sim 20$ & $23.3 \%$ & & $101 \sim 500$ & $46.5 \%$ \\
\hline & $21 \sim 50$ & $19.2 \%$ & & $>500$ & $36.2 \%$ \\
\hline & $>50$ & $8.4 \%$ & & $<100$ & $12.4 \%$ \\
\hline \multirow{4}{*}{ Ownership } & State-owned enterprise & $26.8 \%$ & \multirow{4}{*}{ Sales revenue/million } & $101 \sim 1000$ & $43.6 \%$ \\
\hline & Private enterprise & $46.7 \%$ & & $1001 \sim 10,000$ & $34.7 \%$ \\
\hline & Foreign invested enterprises & $19.6 \%$ & & $>10,000$ & $9.3 \%$ \\
\hline & $\begin{array}{l}\text { Else (collective enterprise } \\
\text { town enterprise, etc.) }\end{array}$ & $6.9 \%$ & & & \\
\hline
\end{tabular}

The exploratory factor analysis of low carbon-based incremental marketing innovation: this study proposed two factor 9 items using principal component analysis, factor loadings is greater than 0.7 , among them minimum factor loading is 0.702 . KMO test value of 9 items is 0.746, chi-square value of Bartlett sphericity test is 202.175 ( $\mathrm{df}$ is 26, p is 0.000), indicating that it is suitable for factor analysis. Each items of two factors significantly correlated at the 0.01 level. Three factors extracted with maximum orthogonal variance (Varimax) rotation explain $65.712 \%$ of the total variance and show that the scale design and results of low carbon-based incremental marketing innovation have good consistency.

The exploratory factor analysis of low carbon-based radical marketing innovation: this study proposed two factor 9 items using principal component analysis, factor loadings is greater than 0.7 , among them minimum factor loading is 0.701 . KMO test value of 9 items is 0.732 , chi-square value of Bartlett sphericity test is 214.352 (df is $26, \mathrm{p}$ is 0.000 ), indicating that it is suitable for factor analysis. Each items of two factors significantly correlated at the 0.01 level. Three factors extracted with maximum orthogonal variance (Varimax) rotation explain $66.625 \%$ of the total variance and show that the scale design and results of low carbon-based radical marketing innovation have good consistency.

The exploratory factor analysis of organizational performance: In this study, two factors 8 items EFA factor analysis, factor loadings is greater than 0.7 , among them minimum load factor is 0.721 . KMO test value of 8 items is 0.806 , chi-square value of Bartlett sphericity test is 185.254 ( $\mathrm{df}$ is $19, \mathrm{p}$ is 0.000 ), indicating that it is suitable for factor analysis. Each items of two factors significantly correlated at the 0.01 level. Three factors extracted with maximum orthogonal variance (Varimax) rotation explain $67.354 \%$ of the total variance and show that the organizational performance scale's design and results have good consistency.

\subsection{Reliability and Validity Test}

We test scale's reliability and validity with Cronbach's $\alpha$ coefficient and confirmatory factor analysis (CFA), in the CFA analysis, the load of factor index, $\mathrm{T}$ value and the average variance extracted (AVE) of each factor, the composite reliability (CR) and $\alpha$ values, all of which the standard load of variable indicators are greater than 0.7 and significantly correlated at the 0.001 level, the AVE values are greater than 0.5 , the CR and $\alpha$ values are greater than 0.7 and show that the scale of each variable has a good reliability and convergent validity.

\subsection{Hypothesis Testing}

The results are shown as Table 2 .

\section{Conclusions}

1) The two elements of the green complex orientation (green market orientation and green innovation orientation) have different significances to two types of low carbon-based marketing innovation (low carbon-based incremental marketing innovation and low carbon-based radical marketing innovation), specifically, green market orientation has a positive and significant influence on the low carbon-based incremental marketing innovation, but the influence on low carbon-based radical marketing innovation is not significant; green innovation orientation has a positive and significant influence on the low carbon-based radical marketing innovation, but the influence on low carbon-based incremental marketing innovation is not significant. This is mainly because various factors of green market orientation and green innovation have different effects on the various factors of low carbon-based incremental marketing innovation and low carbon-based radical marketing innovation.

2) Both low carbon-based incremental marketing innovation and low carbon-based radical marketing inno- 
Table 2. Hypothesis verification (H1-H6).

\begin{tabular}{|c|c|c|c|}
\hline Hypothesis & $\begin{array}{l}\text { Standardized parameter } \\
\text { estimates }\end{array}$ & T value & $\begin{array}{l}\text { Verification } \\
\text { result }\end{array}$ \\
\hline $\begin{array}{l}\text { H1: Green market orientation has significantly positive effects on low carbon-based } \\
\text { incremental marketing innovation. }\end{array}$ & $\gamma 11=0.47$ & $5.21^{* * *}$ & Significant \\
\hline $\begin{array}{l}\mathrm{H} 2 \text { : Green market orientation has significantly positive effects on low carbon-based } \\
\text { radical marketing innovation. }\end{array}$ & $\gamma 21=0.12$ & 1.42 & Not significant \\
\hline $\begin{array}{l}\text { H3: Green innovation orientation has significantly positive effects on low carbon-based } \\
\text { incremental marketing innovation. }\end{array}$ & $\gamma 12=0.15$ & 1.68 & Not significant \\
\hline $\begin{array}{l}\text { H4: Green innovation orientation has significantly positive effects on low carbon-based } \\
\text { radical marketing innovation. }\end{array}$ & $\gamma 22=0.43$ & $4.83^{* * *}$ & Significant \\
\hline $\begin{array}{l}\text { H5: Low carbon-based incremental marketing innovation has significantly positive } \\
\text { effects on organizational performance. }\end{array}$ & $\beta 31=0.27$ & $3.02^{* * *}$ & Significant \\
\hline $\begin{array}{l}\text { H6: Low carbon-based radical marketing innovation has significantly positive effects } \\
\text { on organizational performance. }\end{array}$ & $\beta 32=0.54$ & $5.89^{* * *}$ & Significant \\
\hline
\end{tabular}

Note: ${ }^{* * *}(\mathrm{P}<0.01)$.

vation have a significantly positive effect on organizational performance, however, the effect of low carbonbased radical marketing innovation (path coefficient $=$ 0.54 ) is stronger than low carbon-based incremental marketing innovation (path coefficient $=0.27$ ). The reason is that the low carbon-based incremental marketing innovation is the maintenance innovation, but low carbon-based radical marketing innovation is the source of innovation for competitive advantage. The conclusion supports the viewpoints of scholars such as Adegoke [7], Zhou et al. [5] and Kumar [6], that enterprise which develops innovative products can obtain more profits and higher market share. David [8] and Christensen [9] pointed out that incremental innovation only helped us keep in line with competitors, but the true competitive advantage came from radical innovation. So, it comes a saying from kumar [6] that gradualism is the biggest enemy for innovators.

3) Low carbon-based marketing innovation plays a full mediating effect on the green complex orientation and organizational performance. Specifically, low carbonbased incremental marketing innovation plays a full mediating effect on the green market orientation and organizational performance, while low carbon-based radical marketing innovation plays a full mediating effect on green innovation orientation and organizational performance. It is mainly the reason that the two orientation factors play different effects on various factors of the two kinds of low carbon-based marketing innovation.

4) The Cross-sectoral coordination factors of the green market orientation and the innovation spirituality of green innovation orientation factors have a positive and significant influence on the low carbon-based incremental marketing innovation and low carbon-based radical marketing innovation.

\section{Acknowledgements}

This paper was supported by "The protection and livelihood improvement of metropolis water source".

\section{REFERENCES}

[1] P. M. Simpson, J. A. Siguaw and C. A. Enz, "Innovation Orientation Outcomes: The Good and the Bad," Journal of Business Research, Vol. 59, No. 10-11, 2006, pp. 1133-1141.

[2] P. R. Berthon, J. M. Hulbert and L. F. Pitt, "To Serve or Create? Strategic Orientations toward Customers and Innovation," California Management Review, Vol. 42, No. 1, 1999, pp. 37-58.

[3] C. M. Da, "Market Information Processing Program and Organizational Memory Impact of Marketing Innovation," Taiwan's National Chengchi University Doctoral Thesis, 2001, pp. 12-68.

[4] L. X. Jiang, "Marketing Innovation'S Mediating Effect on the Relationship between Market Orientation and Marketing Performance," Management Review, Vol. 21, No. 11, 2009, pp. 52-58.

[5] K. Z. Zhou, C. K. (Bennett) Yim and D. K. Tse, "The Effects of Strategic Orientations on Technology and Market-Based Breakthrough Innovations," Journal of Marketing, Vol. 69, No. 4, 2005, pp. 42-60.

[6] Kumar, "Marketing Mentality Change-Seven Innovation for Marketing Reengineering Brilliant," Commercial Press, Shanghai, 2006, pp. 204-230.

[7] O. Adegoke, "Innovation Types and Innovation Management Practices in Service Companies," International Journal of Operations \& Production Management, Vol. 27, No. 6, 2007, pp. 564-587.

[8] B. L. David, "How Internal Venture Groups Innovate," Research-Technology Management, 1998, pp. 38-43.

[9] C. M. Christensen, "The Innovator's Dilemma," Harvard Business School Press, Boston, 1997, pp. 21-150. 